\title{
Virtual reality as a training tool in engineering education.
}

\begin{abstract}
This paper presents a new desktop training tool in Flexible Manufacturing Cell (FMC) to demonstrate and address the concept of reconfigurability of Flexible Manufacturing System (FMS). It is a robot-centred desktop virtual system with three main elements consisting of a milling machine, a storage system and a six degrees of freedom articulated robot. Visual C++ and OpenGL are used for user interface, simulation and animation. During simulation, the elements of the FMC are re-configured by changing the position of the storage system through the configuration interface. This system can provide visualisation of the reconfiguration process of the FMC and a good training tool for students.
\end{abstract}

Keyword: Engineering education; Flexible Manufacturing Cell; FMC; Training; Virtual Reality; VR. 